\title{
Reforma trabalhista: contrato intermitente e trabalho feminino
}

\author{
Labor reform: intermitting contract and female work \\ Reforma laboral: contrato intermitente y trabajo feminino \\ Flávia Traldi de Lima' \\ Gustavo Tank Bergström ${ }^{2}$ \\ Sandra Francisca Bezerra Gemma ${ }^{3}$
}

Received: 29.04 .2020

Accepted: 22.05 .2020

https://doi.org/10.33239/ritdh.v3.66

1 Pesquisadora colaboradora no Laboratório de Ergonomia, Saúde e Trabalho (ERGOLAB) da Faculdade (FCA/UnICAMP) Ciencias Aplicadas (FCA/UNICAMP) e no Núcleo de Subjetividade (NETSS) Traho, Saúde e Subjetividade (NETSS) da Faculdade de Educação (FE/UNICAMP). Educação da Universidade Estadual Educação da Universidade Estadual de Campinas (FE/UNICAMP). Mestra pelo Programa Interdisciplinar em
Ciências Humanas e Sociais Ciencias Humanas e Sociais
Aplicadas pela Universidade Estadual de Campinas UNICAMP. Graduação em Psicologia.

https://orcid.org/0000-0002-6389-4764

$2 \quad$ Mestrando no programa interdisciplinar de Ciências Humanas e Sociais Aplicadas na (UNICAMP) e pesquisador do Laboratório de Ergonomia, Saúde e Trabalho (ERGOLAB) na mesma faculdade. Especialista em Direito e Processo do Trabalho. Advogado.

https://orcid.org/0000-0003-0648-6278

3 Professora plena do Curso de Mestrado Interdisciplinar em Ciências Humanas e Sociais Aplicadas da Faculdade de Ciências Aplicadas da Universidade Estadual de Campinas, onde também é Coordenadora do Laboratório de pesquisa em
Ergonomia, Saúde e Trabalho ERGOLAB).

https://orcid.org/0000-0002-8567-157X

\section{$(\mathrm{cc}) \mathrm{Br}$}

This work is licensed under a Creative Commons Attribution 4.0 International License.

\section{RESUMO}

Ao discorrer sobre a evolução histórica da legislação referente à proteção do trabalho feminino, percebem-se, entre avanços e retrocessos, poucos efeitos práticos no empreendimento de uma verdadeira ruptura com os processos de desigualdade de gênero. Do mesmo modo, a recente Reforma Trabalhista vem demonstrando incapacidade em dissolver a reprodução de tais padrões ao flexibilizar as normas sociais do trabalho. Frente a isso, o artigo tem por objetivo apresentar as alterações legislativas da Reforma Trabalhista que culminaram em impactos à força de trabalho feminina, especialmente referentes ao contrato intermitente. Para isso realizou-se pesquisa documental a despeito das legislações anteriores e vigentes, bem como revisão de literatura de estudos desenvolvidos sobre a Reforma Trabalhista após sua promulgação, articuladas a aportes teóricos das ciências humanas e sociais que discutem a divisão sexual do trabalho e a segregação entre homens e mulheres no trabalho. Assim como os trabalhos flexíveis do tipo parcial e temporário, o contrato intermitente segue inserindo mulheres em atividades segregadas de baixa qualificação, escolaridade e renda, produzindo dinâmicas semelhantes em termos de precarização e intensificação do trabalho que comprometem, sobretudo, a conciliação entre vida familiar e laboral.

PALAVRAS-CHAVE: Reforma Trabalhista, contrato intermitente, trabalho feminino.

\section{ABSTRACT}

In discussing the historical evolution of legislation on the protection of women's work, one can see, between advances and setbacks, little practical effect on the undertaking of a real break with the processes of gender inequality. Similarly, the recent Labor Reform has shown an inability to dissolve the reproduction of such patterns by making social labour standards more flexible. In view of this, the article aims to present the legislative changes of the Labor Reform that culminated in impacts on the female labor force, especially with regard to intermittent contracts. To this end, documentary research was carried out in spite of previous and current legislation, as well as a literature review of studies developed on the Labor Reform after its enactment, articulated to theoretical contributions from the human and social sciences that discuss the sexual division of labor and segregation between men and women at work. Like flexible partial and temporary work, the intermittent contract continues to include women in segregated activities with low qualifications, schooling and income, producing similar dynamics in terms of precariousness and intensification of work that compromise, above all, the conciliation between family and work life.

\section{KEYWORDS: Labour Reform, intermittent contract, female labor.}

\section{RESUMEN}

Al examinar la evolución histórica de la legislación sobre la protección del trabajo de la mujer, se observa, entre avances y retrocesos, poco efecto práctico en la realización de una verdadera ruptura con los procesos de desigualdad de género. Asimismo, la reciente reforma laboral ha demostrado la incapacidad de disolver la reproducción de esos patrones haciendo más flexibles las normas laborales sociales. En vista de ello, el artículo tiene por objeto presentar los cambios legislativos de la Reforma Laboral que culminaron en repercusiones en la fuerza de trabajo femenina, especialmente en lo que respecta a los contratos intermitentes. Para ello se realizó una investigación documental a pesar de la legislación anterior y actual, así como una revisión bibliográfica de los estudios desarrollados sobre la Reforma Laboral después de su 
promulgación, articulados a aportaciones teóricas de las ciencias humanas y sociales que discuten la división sexual del trabajo y la segregación entre hombres y mujeres en el trabajo. Al igual que el trabajo parcial y temporal flexible, el contrato intermitente sigue incluyendo a las mujeres en actividades segregadas de baja calificación, escolaridad e ingresos, produciendo dinámicas similares en cuanto a la precariedad e intensificación del trabajo que comprometen, sobre todo, la conciliación entre la vida familiar y laboral.

PALABRAS CLAVE: Reforma laboral, contrato intermitente, trabajo femenino.

\section{INTRODUÇÃO}

De grande marco histórico na proteção de direitos fundamentais dos trabalhadores, a Constituição Federal de 1988 recepcionou a Consolidação das Leis do Trabalho - CLT e sedimentou em seu texto o reconhecimento da dignidade humana do trabalhador, sempre visando a melhoria de sua condição social. Se de um lado celebrava-se a conquista do proletariado, do outro, setores patronais tomados pelo imperativo econômico buscavam impelir o rebaixamento dos recentes direitos conquistados. O impulso por desregulamentação, aliás, sempre foi um vetor ativo em nosso país, especialmente após 1988.

A aprovação da Reforma Trabalhista apresenta-se exatamente como marco temporal de desregulamentação, que tarda em permanecer ${ }^{1}$. Ao levar os pensamentos para o ano de 2017, é de fácil lembrança o argumento propagandista em prol da reforma que se formava. Cristalizouse na sociedade a ideia de que a legislação trabalhista no Brasil era demasiadamente arcaica e necessitava modernizar-se para atender às novas demandas do mercado. Em tempos de relações voláteis, a vida contemporânea demonstra a experiência de uma população heterônoma, confrontada e possivelmente sobrepujada por forças que não controla ou entende totalmente ${ }^{2}$. Dessa forma, a impressão que fica é que aqui, em terras tupiniquins, precisamos de mudança, independente do que se mude.

De fato, a CLT tem mais de setenta e cinco anos. No entanto, o conceito de que as relações de trabalho no país eram regidas por norma de 1943 procede ${ }^{3}$ Não, não procede.

\footnotetext{
${ }^{1}$ Precisamente, quatro alterações significativas ocorreram desde novembro/2017, quando a Reforma Trabalhista entrou em vigor, sendo, a "reformulação" das Normas Regulamentadoras, a lei da Liberdade Econômica, a CTPS verde e amarela (caducada por questões políticas) e a MP 927/2020 (em conta do COVID-19), todas de alcance federal.

${ }^{2}$ BAUMAN, Zygmunt. Tempos líquidos. Trad. de Carlos Alberto Medeiros. Rio de Janeiro: Ed. Jorge Zahar, 2007.

${ }^{3}$ Na obra "Comentários à Reforma Trabalhista", em parte intitulada como "Nota do Autor", Homero Batista questiona: "E, afinal, procede a informação de que as relações de trabalho no Brasil de 2017 eram
} 
Desde sua promulgação, na era Vargas, foram mais de quinhentas implementações, que atualizaram e desenvolveram sua estrutura, englobando tanto questões de direito material, quanto questões de direito processual. Cita-se, a exemplo, o regime do fundo de garantia de 1967; o capítulo relativo às férias de 1977; os inúmeros direitos previstos na $\mathrm{CF} / 88$, o banco de horas na reforma de 1998; a alteração das relações sindicais em 2008. Defender o arcaísmo da CLT seria, portanto, negligenciar a própria história.

No entanto, cá estamos. Já se passaram mais de dois anos desde que a reforma entrou em vigor. E hoje, podemos dizer que temos uma legislação do trabalho atualizada? Não, também não podemos. A tramitação açodada da reforma igualmente mitigou diversos assuntos que necessitavam de atualização. A proteção e promoção do trabalho feminino, o capítulo de segurança e medicina do trabalho e a modificação do nosso sistema sindical são apenas alguns exemplos que colocam em dúvida a real motivação da proposta de reformulação da legislação do trabalho.

Os impactos da reforma, portanto, são diversos. Dentre as mais pertinentes consequências da nova vinculação jurídica às quais estão submetidos os trabalhadores destacam-se as alterações das normas asseguradoras dos direitos das mulheres. Seja por alterações diretas, como as modificações referentes a jornada de trabalho ${ }^{4}$, seja por modificações indiretas, como a inédita possibilidade do contrato intermitente ${ }^{5}$, estudos recentes apontam efeitos nefastos trazidos para o labor feminino, bem como, a ampliação da desigualdade de gênero.

Dessa maneira, objetivou-se neste artigo apresentar os impactos que a Reforma Trabalhista trouxe à força de trabalho feminino, especialmente na possibilidade inédita de admissão por contrato intermitente. Para tanto, foi analisado o desenvolvimento da legislação trabalhista, principalmente a relativa à proteção do trabalho da mulher, além de revisão de literatura de estudos desenvolvidos após a vigência da reforma, com articulação aos aportes teóricos das ciências humanas e sociais que discutem a divisão sexual do trabalho e o papel atribuído à mulher, tanto na sociedade, quanto na atividade laboral.

regidas por norma de 1943?" (BATISTA, Homero Mateus da Silva. Comentários à Reforma Trabalhista: Análise da Lei 13.456/2017- Artigo por Artigo. São Paulo: Revista dos Tribunais, 2017. p. 7).

${ }^{4}$ A citar a revogação do artigo 384 da CLT: "Em caso de prorrogação do horário normal, será obrigatório um descanso de 15 (quinze) minutos no mínimo, antes do início do período extraordinário do trabalho" ${ }^{5}$ Artigos 443 e 452-A da CLT. 
Revista Jurídica Trabalho e Desenvolvimento Humano Procuradoria Regional do Trabalho da 15a Região

\section{PROTEÇÃO LEGAL AO TRABALHO DA MULHER}

O Direito do Trabalho nasceu por necessidade humanitária ${ }^{6}$ e foi construído sob as égides de décadas de reivindicações do proletariado, apoiado no fortalecimento dos sindicatos e estabelecimento das instituições públicas. Sua existência se fez necessária no processo histórico para retificar as distorções econômico-sociais do capitalismo e civilizar a importante relação de poder que sua dinâmica econômica cria no âmbito da sociedade civil ${ }^{7}$. O resultado se faz presente em uma cultura jurídica laboral que incansavelmente busca a aproximação das necessidades sociais às próprias relações de trabalho.

A CLT, nesse sentido, foi promulgada em 1ำ de maio de 1943 e unificou toda a legislação laboral existente à época, tornando-se o principal instrumento garantidor de direitos aos trabalhadores espalhados Brasil afora. Desde então, contempla um capítulo próprio para a proteção do trabalho da mulher, onde encontram-se entre os artigos 372 a 401-B disposições específicas para a promoção do trabalho feminino, sua inserção no mercado de trabalho, além do provimento de condições especiais que levam em conta as características próprias do sexo feminino, sobretudo as relacionadas à maternidade.

Dois argumentos fundamentais pautaram o desenvolvimento da legislação referente a proteção do trabalho da mulher, sendo eles: (a) as de ordem fisiológica, uma vez que geralmente as mulheres não possuem a mesma resistência física que os homens; (b) as de ordem social, em face da histórica discriminação perpetrada em relação à mulher, incluído as relações de trabalho. Não por acaso, ao reconhecermos que a construção de gênero é um processo ideológico e cultural contínuo com uma longa história, o foco se desloca para a análise dos processos sociais envolvidos ${ }^{8}$ e, assim, em todos os sistemas jurídicos, a mulher merece

\footnotetext{
${ }^{6}$ Segundo Raimundo Simão de Melo, "o Direito do Trabalho nasceu por necessidade humanitária de se regulamentar as relações de trabalho entre empregados e empregadores, visando a proteção destes, em especial contra sua exposição às mais indignas e desumanas condições de trabalho, como jornadas excessivas, não existência de salário mínimo suficiente a manutenção das suas necessidades, seguridade social para os momentos de invalidez, velhice e outras necessidades fundamentais do ser humano." (MELO, Raimundo Simão de. Impactos da Reforma Trabalhista sobre o Meio Ambiente do Trabalho e a Saúde dos Trabalhadores. Revista do Advogado, n. 137, p.144-153, mar. 2018, p. 145.)

${ }^{7}$ DELGADO, Mauricio Godinho. Curso de direito do trabalho. 13. ed. São Paulo: LTr, 2014, p. 83.

${ }^{8}$ WAJCMAN, J. Tecnologia de produção: fazendo um trabalho de gênero. Cadernos Pagu, n. 10, p. 201256, 1 jan. 2012, p. 227.
} 
tratamento particular, asseguradas condições mínimas de trabalho, diferentes e voltadas para a diminuição das assimetrias fisiológicas e sociais estabelecidas em relação aos homens ${ }^{9}$.

Por esta razão, a Constituição Federal de 1988 prevê em seu artigo 7ำ, inciso XX, a garantia de "proteção do mercado de trabalho da mulher, mediante incentivos específicos, nos termos da lei". O dispositivo em questão representa a concretização do Princípio da Igualdade, segundo o qual os desiguais devem ser tratados na medida de sua desigualdade. Exatamente neste contexto é que repousa a justificativa para o desenvolvimento de normatização que busca o equilíbrio na assimetria existente entre os gêneros. Dessa maneira, o texto constitucional não só procura estabelecer a proteção da mulher, mas, igualmente a promoção do trabalho feminino, tendo como norte a isonomia ao labor masculino.

Exemplos não faltam. A CLT impediu expressamente a exigência de atestado/exame de gravidez ou de esterilidade, tanto para a admissão quanto para a continuidade no emprego (inciso IV do art. 373-A), proibindo que a maternidade sirva de discriminação da mulher. Nessa linha, a CLT ainda garante estabilidade provisória em conta de gravidez advinda no curso do contrato de trabalho (art. 391-A), estendendo a estabilidade ao empregado adotante (art. 391A, parágrafo único), licença maternidade (art. 392), rescisão contratual em caso de trabalho prejudicial à gestação, sem cumprimento de aviso prévio (art. 394), entre outros dispositivos presentes na Seção V.

Medidas voltadas a coibir a discriminação e promover o trabalho feminino também se fizeram presentes, a citar a vedação do oferecimento de emprego com referência ao sexo e situação familiar. Da mesma maneira, a proibição de recusa de emprego, promoção, dispensa ou qualquer outra forma de distinção remuneratória estabelecido pelos mesmos critérios. Visando se aproximar da isonomia de condições, a CLT expressamente permite a "adoção de medidas temporárias que visem ao estabelecimento das políticas de igualdade entre homens e mulheres, em particular as que se destinam a corrigir as distorções que afetam a formação profissional, o acesso ao emprego e as condições gerais de trabalho da mulher" (parágrafo único do artigo 373-A).

Pelas diferentes condições fisiológicas que predominam nos gêneros, o limite de carregamento de peso permitido durante a execução das tarefas da mesma forma difere. Para as mulheres, é vedado o emprego de força muscular superior a 20 quilos para o trabalho

\footnotetext{
${ }^{9}$ NASCIMENTO, Amauri Mascaro. Curso de direito do trabalho. São Paulo: Saraiva, 14. ed., 2013, p. 201.
} 
contínuo, ou 25 quilos para o trabalho ocasional (art. 390 da CLT), sendo que, para os homens, o limite foi estabelecido em 60 quilos (art. 198 da CLT). Ainda com relação às conjunturas fisiológicas, somadas à dupla jornada à qual as mulheres estão submetidas dado o contexto social estabelecido, quando havia prorrogação do horário normal, o art. 384 da CLT previa repouso de no mínimo de 15 minutos antes do início do período extraordinário do trabalho. Este último dispositivo, contudo, integrou o time das revogações na Reforma Trabalhista e deixou de fazer parte de nossa legislação.

Diante da síntese legal aqui compilada, mesmo que timidamente, percebe-se que desenvolvimentos de setores da sociedade refletiram na construção legal, especialmente ao reconhecer nas mulheres suas particularidades. No entanto, embora a legislação trabalhista, ao tutelar o trabalho da mulher, tenha proposto tratamento adequado com vistas ao desenvolvimento de uma sociedade justa, verifica-se que ainda persistem as desigualdades. De acordo com o relatório sobre igualdade do Fórum Econômico Mundial, vislumbra-se que ainda serão necessários aproximadamente 250 anos para que haja igualdade entre homens e mulheres no mercado de trabalho ${ }^{10}$.

\section{FLEXIBILIZAÇÃO DAS NORMAS TRABALHISTAS}

A Reforma Trabalhista é assunto que ainda divide opiniões. Seu início se deu em agosto de 2016 quando, após um desgastante e controverso processo de Impeachment, Michel Temer assumiu a presidência do país e levou ao congresso a redação do PL 6.787-B, de $2016^{11}$ - que tramitou como PLC 38, de $2017^{12}$. O texto inicial, que propunha a alteração de sete artigos, foi recepcionado com relatoria do então Deputado Federal Rogério Marinho (PSDB-RN).

10 FÓRUM ECONÔMICO MUNDIAL. Global Gender Gap Report 2020. Genebra, 2020. Disponível em:<http://www3.weforum.org/docs/WEF GGGR 2020.pdf? ga=2.248336903.1636901091.158706499 5-1004197514.1587064995>. Acesso em 22 abr. 2020.

${ }^{11}$ BRASIL. Poder Executivo. Projeto de Lei no. 6.787-B, de 23 de dezembro de 2016. Altera o Decreto-Lei no 5.452, de 10 de maio de 1943 - Consolidação das Leis do Trabalho, e a Lei no 6.019 , de 3 de janeiro de 1974, para dispor sobre eleições de representantes dos trabalhadores no local de trabalho e sobre trabalho temporário, e dá outras providências.

12 BRASIL. Câmara dos Deputados. Projeto de Lei da Câmara no. 38, de 28 de abril de 2017. Altera a Consolidação das Leis do Trabalho (CLT), aprovada pelo Decreto-Lei no 5.452, de 10 de maio de 1943, e as Leis nos 6.019, de 3 de janeiro de 1974, 8.036, de 11 de maio de 1990, e 8.212, de 24 de julho de 1991, a fim de adequar a legislação às novas relações de trabalho.

LIMA, Flávia T. de; BERGSTRÖM, Gustavo Tank; GEMMA, Sandra F. Bezerra. Reforma trabalhista: contrato intermitente e trabalho feminimo. Revista Jurídica Trabalho e Desenvolvimento Humano, Campinas, v. 3, p. 1-19, 2020. 
Revista Jurídica Trabalho e Desenvolvimento Humano Procuradoria Regional do Trabalho da 15a Região

Anunciada com apoio de setores da mídia sob as superficiais justificativas de geração de empregos e da eminente necessidade de modernização do conjunto de normas que regulamentavam as relações de trabalho ${ }^{13}$, as aspirações do Poder Executivo geraram diversas polêmicas e discussões polarizadas na sociedade. Por outro lado, contrariando este cenário, o debate na Casa do Povo ficou marcado por sua superficialidade e pouca representatividade, uma vez que a tramitação açodada deixou de contar com diversos setores envolvidos em questões trabalhistas de âmbito nacional. O resultado foi a apresentação pelo relator de um texto indicando a surpreendente modificação de mais de cem pontos na legislação trabalhista.

Em votação do texto-base sobre a reforma tramitado em sessão da Câmara dos Deputados no dia 26 de abril de 2017, das 51 mulheres parlamentares, 26 votaram sim para o texto e 25 votaram não, em semelhante grau de divisão de julgamentos. Tal fato representa importante questão para a explicação da contínua exclusão das mulheres.

Aprovado pela Câmara do Deputados e encaminhado ao Senado Federal, a mesma sintomática antidemocrática prevaleceu. Mesmo diante da apresentação de mais de 800 emendas ao projeto original, a votação na casa acabou por rejeitá-las integralmente. Dessa maneira, a aprovação integral do texto do projeto estava sedimentada pelo Poder Legislativo e seguia para a sanção sem vetos de Michel Temer. Em menos de quatro meses de tramitação, a Reforma Trabalhista estava aprovada e ganhava número: Lei n. 13.467 de 2017.

Dentre as mais variadas alterações, destacou-se a inédita possibilidade da celebração de contrato de trabalho intermitente. A nova modalidade classificou-se como aquela em que a prestação de serviços, com subordinação, não é contínua, ocorrendo com alternância de períodos de prestação de serviços e de inatividade, determinados em horas, dias ou meses, independentemente do tipo de atividade do empregado e do empregador (artigo 443, § 3 da CLT). São características do contrato de trabalho intermitente a forma escrita obrigatória, com especificação do salário-hora, que não poderá ser inferior ao mínimo ou ao dos que exerçam a mesma função (artigo 452-A, caput). O empregador deve convocar o empregado com pelo

\footnotetext{
${ }^{13}$ Em entrevista televisiva, o então deputado federal Rogério Marinho (PSDB-RN) justificou a necessidade de modernização da legislação do trabalho: “Nós temos uma lei de 1943. Às vezes, a gente é chamado de conservador aqui neste Parlamento. Conservador é quem não quer mudar. Então, tem gente que está apegado a uma lei de 70 anos. Uma lei anacrônica, antiga, uma lei que não tem mais nada a ver com o espírito do tempo". Em: REPÓRTER BRASIL. Reforma trabalhista: maior parte da mídia não aborda o impacto negativo das mudanças. Publicado pela Repórter Brasil em 05 de junho de 2017. Disponível em: <https://reporterbrasil.org.br/2017/06/reforma-trabalhista-maior-parte-da-midia-nao-aborda-oimpacto-negativo-das-mudancas>. Acesso em: 20 abr. de 2020.
}

LIMA, Flávia T. de; BERGSTRÖM, Gustavo Tank; GEMMA, Sandra F. Bezerra. Reforma trabalhista: contrato intermitente e trabalho feminimo. Revista Jurídica Trabalho e Desenvolvimento Humano, Campinas, v. 3, p. 1-19, 2020. 
Revista Jurídica Trabalho e Desenvolvimento Humano Procuradoria Regional do Trabalho da 15a Região

menos três dias corridos de antecedência $(\S 1$ 으), cabendo a ele responder ao chamado em um dia útil, presumindo-se recusada a oferta em caso de silêncio ( $§ 2^{\circ}$ ), sem que isso descaracterize a subordinação (§ 3ํ). Há ainda, a autorização legal para multa pecuniária ao empregado que faltar ao ser chamado, no valor de metade da diária a que teria direito se houvesse comparecido (§ 4ㅇ), o empregado pode prestar serviços a outros contratantes ( $5^{5} \circ$ ) e deve auferir ( $(6 \circ)$, depois de cada período de prestação de serviços e mediante recibo (§ 7ㅇ), a remuneração acrescida de férias mais $1 / 3,13$ o salário, RSR e adicionais. Impõe-se o recolhimento da contribuição previdenciária e do FGTS e a entrega da documentação ao empregado ( $\S 8$ \&), além da garantia de um mês de férias (§ 9ㅇ).

Percebe-se que as inovações trazidas pelo contrato de trabalho intermitente abalaram os alicerces do Direito do Trabalho em vários aspectos ${ }^{14}$. Afinal, o conceito constitucional de salário-mínimo dificilmente se coaduna com o contrato zero-hora ${ }^{15}$, já que submete o trabalhador a um fato aleatório imponderável, além de limitar seu acesso ao seguro desemprego, à renda ou benefício previdenciário ${ }^{16}$. Ademais, o que se aventou em termos de modernização das relações de trabalho e geração de emprego não tem sido demonstrado na realidade. Pelo contrário, ao ampliar a flexibilização das normas sociais do trabalho, o que se tem apresentado como resultado prático é a substituição de relações de emprego protegidas por postos de trabalho precários ${ }^{17}$.

Sobre os impactos da medida para a classe trabalhadora feminina, especificamente, Marilane Oliveira Teixeira et al. ${ }^{18}$ aponta a aplicação da reforma como um incentivo às novas formas de exclusão e desigualdade, sobretudo para as mulheres negras, trabalhadoras rurais e trabalhadoras domésticas. Para a autora, as formas de flexibilização do trabalho de que se faz crítica em termos de gênero se realizam na expansão das possibilidades de contrato, como o trabalho intermitente, dado que as mulheres já são maioria dentre os contratados entre os

\footnotetext{
${ }^{14}$ HIGA, Flávio da Costa. Reforma trabalhista e contrato de trabalho intermitente. Consultor Jurídico, 8 de junho de 2017. Disponível em: <https://www.conjur.com.br/2017-jun-08/flavio-higa-reformatrabalhista-contrato-trabalho-intermitente\# ftn11>. Acesso em: 20 de abril de 2020.

${ }^{15} \mathrm{O}$ contrato zero hora baseia-se na expressão "zero-hour contract" do direito inglês, uma vez que deflagra como principal característica a não há garantia de prestação de serviços e de recebimento de salário.

${ }^{16}$ BATISTA, Homero Mateus da Silva. CLT Comentada. 2. ed. São Paulo: Revista dos Tribunais, 2018, p. 303.

${ }^{17}$ KREIN, José Dari; OLIVEIRA, Roberto Veras; FILGUEIRAS, Vitor Araújo (Orgs). Reforma trabalhista no Brasil: promessas e realidade. Campinas: Curt Nimuendajú, 2019.

${ }^{18}$ TEIXEIRA, Marilane O. A reforma trabalhista e as mulheres. In: TEIXEIRA, Marilane O. (Org). Contribuição crítica à reforma trabalhista. Campinas, SP: UNICAMP/IE/CESIT, 2017, p. 237-261.
} 
Revista Jurídica Trabalho e Desenvolvimento Humano Procuradoria Regional do Trabalho da 15a Região

trabalhadores parciais e terceirizados. Essa assertiva corrobora o que Ricardo Antunes ${ }^{19}$ afirma, qual seja, de que os processos de terceirização e flexibilização aumentam ainda mais a fragmentação, heterogeneização e divisão intraclasse trabalhadora.

Em relação às estatísticas que se tem até aqui sobre o tema, dados do Cadastro Geral de Empregados e Desempregados (CAGED) demonstraram que entre novembro de 2017 e junho de 2019, quanto aos percentuais de indivíduos contratados como intermitentes frente aos respectivos totais de admitidos, obteve-se $0,58 \%$ para os homens e $0,51 \%$ para mulheres. Por meio do gráfico abaixo é possível verificar as proporções de homens e mulheres admitidos no período.

Gráfico 1: Trabalho Intermitentes: proporções dos totais de admitidos segundo o sexo Masculino e Feminino (\%) - nov/2017 a jun/2019

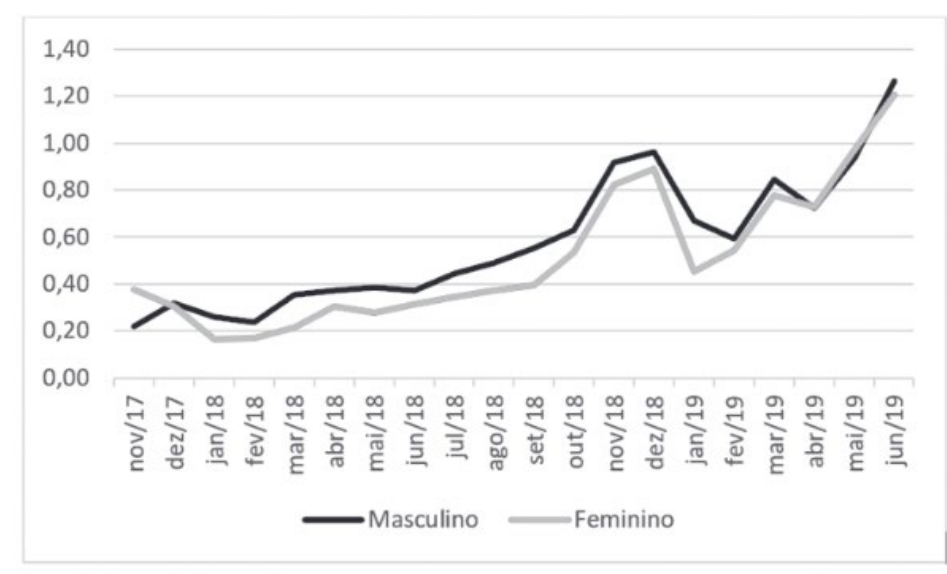

Fonte: Dados CAGED sistematizados por de José Dari Krein e Roberto Veras de Oliveira $^{20}$

Embora a porcentagem masculina tenha sido superior entre os indivíduos contratados como intermitentes frente aos respectivos totais de admitidos, verifica-se que, de modo geral no período analisado, houve ligeiras e constantes aproximações em relação às admissões

\footnotetext{
${ }^{19}$ ANTUNES, Ricardo. O privilégio da servidão: o novo proletariado de serviços na era digital. São Paulo: Boitempo, 2018, p. 150.

${ }^{20}$ KREIN, José Dari; OLIVEIRA, Roberto Veras. Para além do discurso: impactos efetivos da Reforma nas formas de contratação. In KREIN, José Dari; OLIVEIRA, Roberto Veras; FILGUEIRAS, Vitor Araújo (Orgs). Reforma trabalhista no Brasil: promessas e realidade. Campinas: Curt Nimuendajú, 2019, p. 92.
} 
Revista Jurídica Trabalho e Desenvolvimento Humano Procuradoria Regional do Trabalho da 15a Região

femininas. No primeiro mês de vigor da Reforma Trabalhista em 2017, por exemplo, as mulheres lideraram os homens na proporção entre os admitidos na modalidade intermitente.

Quanto à distribuição dos admitidos para trabalho intermitente, segundo o grau de instrução e faixa etária, os dados do CAGED também apontam que a maioria dos sujeitos contratados eram jovens-adultos, com nível médio de escolaridade. Observa-se ainda, que as ocupações com maior incidência no trabalho intermitente estão relacionadas ao setor de serviço e comércio, sendo que os níveis de qualificação, assim como os padrões de remuneração apresentam-se predominantemente baixos ${ }^{21}$.

O perfil mulher, jovem-adulta, com baixa qualificação, inserida em setores de serviço e comércio é uma categoria há tempos estudada por sua expressiva associação a modalidades de trabalho precários, do tipo informal e parcial ${ }^{22}$. Este fator indica que as mulheres são mais atingidas pela precariedade no trabalho quando comparada aos homens. Sendo o trabalho intermitente também uma forma de trabalho indeterminado, vulnerável e destituída de direitos fundamentais, propõe-se discutir, a partir da mesma articulação social de sexo, de classe e de ocupações, seus impactos para a força de trabalho feminina.

\section{TRABALHO FEMININO E DIVISÃO SEXUAL DO TRABALHO}

Cristina Bruschini e Maria Rosa Lombardii23, Angela Maria Carneiro Araújo e Verônica Clemente Ferreira ${ }^{24}$, Márcia de Paula Leite ${ }^{25}$ e Magda de Almeida Neves ${ }^{26}$ são estudiosas que caracterizam a inserção da mulher em trabalhos flexíveis, tipicamente precários, instáveis e mal

\footnotetext{
${ }^{21}$ KREIN, José Dari; OLIVEIRA, Roberto Veras. Para além do discurso: impactos efetivos da Reforma nas formas de contratação. In KREIN, José Dari; OLIVEIRA, Roberto Veras; FILGUEIRAS, Vitor Araújo (Orgs). Reforma trabalhista no Brasil: promessas e realidade. Campinas: Curt Nimuendajú, 2019, p. 94-97.

22 HIRATA, Helena. Globalização, trabalho e gênero. Revista de Políticas Públicas, vol. 9, n. 1, p. 111-128, 2005.

23 BRUSCHINI, Cristina; LOMBARDI, Maria Rosa. A bipolaridade do trabalho feminino no Brasil contemporâneo. Cad. Pesqui., São Paulo, n. 110, p. 67-104, 2000.

${ }^{24}$ ARAÚJO, Angela Maria Carneiro; FERREIRA, Verônica Clemente. Terceirização e relações de gênero. In: DAU, Denise Motta; RODRIGUES, Iram Jácome; CONCEIÇÃO, Jefferson José da (Orgs.) Terceirização no Brasil: do discurso da inovação à precarização do trabalho (atualização do debate e perspectivas). São Paulo: Ed. Annablume, CUT, 2009. p. 129-147, 2009.

25 LEITE, Marcia de Paula. As bordadeiras de Ibitinga: trabalho a domicílio e prática sindical. Cadernos Pagu, Campinas, n. 32, p. 183-214, 2009.

${ }^{26}$ NEVES, Magda de Almeida. Trabalho feminino, flexibilidade e qualificação. Trabalho e Educação, Belo Horizonte, v. 21, n. 2, p. 11-28, 2012.
} 
Revista Jurídica Trabalho e Desenvolvimento Humano Procuradoria Regional do Trabalho da 15a Região

remunerados, atrelando tal fato às desigualdades ainda vigentes entre homens e mulheres no trabalho.

Para Helena Hirata ${ }^{27}$, mudanças no contexto internacional como a globalização e a divisão sexual do trabalho, impulsionadas pela conjuntura neoliberal, incidem como fenômenos substanciais ao desenvolvimento crescente da crise do emprego, bem como da precariedade no trabalho e da inserção da mulher como categoria elementar. De acordo com a autora, isso significa dizer que fatores advindos das crises das últimas décadas como privatizações, diminuição da proteção social associada e o incentivo à financeirização se associam ao crescimento do emprego vulnerável em uma perspectiva de gênero que marca a existência de uma divisão sexual do trabalho.

A divisão sexual do trabalho é entendida como a forma de divisão do trabalho social decorrente das relações sociais de sexo, tendo por característica a destinação dos homens à esfera produtiva com forte valor agregado e às mulheres, esfera reprodutiva, destinada às atividades necessárias para garantir a manutenção e reprodução da força de trabalho ${ }^{28}$. Segundo Danièle Kergoat ${ }^{29}$, existem dois princípios organizadores na forma da divisão sexual do trabalho. O primeiro princípio, de separação, está associado à noção de que existem trabalhos de homens e trabalhos de mulheres, e o segundo princípio, de hierarquização, de que o trabalho do homem "vale" mais do que o trabalho da mulher.

Tais princípios são legitimados por uma ideologia naturalista, estritamente biológica, que se sobrepõe à concepção de gênero, reduzindo as práticas sociais a papéis sexuados. Isso significa que existe uma construção social e histórica que produz representações de feminino e de masculino que influencia a inserção de homens e mulheres em determinadas categorias, setores e ocupações no trabalho. Na prática, esse fenômeno reverbera de diversas maneiras.

Embora tenha ascendido a presença de mulheres em posições técnicas ou de chefia, que Ihes conferem alto grau de escolaridade, evidencia-se o fato de receberem salários incompatíveis com os salários da classe masculina. Em 2018, as mulheres representavam 45,3\%

\footnotetext{
${ }^{27}$ HIRATA, Helena. Globalização, trabalho e gênero. Revista de Políticas Públicas, vol. 9, n. 1, p. 111-128, 2005.

${ }^{28}$ HIRATA, Helena; KERGOAT, Danièle. Divisão sexual do trabalho profissional e doméstico: Brasil, França, Japão. In: Costa, Albertina de Oliveira et al. (Orgs.). Mercado de trabalho e gênero: comparações internacionais. Rio de Janeiro: Editora FGV, 2008, p. 263-278.

${ }^{29}$ KERGOAT, Danièle. Divisão sexual do trabalho e relações sociais de sexo. In: HIRATA, Helena; LABORIE, Françoise ; LE DOARE, Hélène, SENOTIER, Danièle. (Orgs). Dicionário Crítico do feminismo. São Paulo: Edunesp, 2009.
} 
da força de trabalho, ganhavam $79.5 \%$ do total do salário pago ao homem. O rendimento médio total das mulheres ocupadas com idade entre 25 e 49 anos era de $R \$ 2.050$, enquanto o dos homens chegava a $\mathrm{R} \$ 2.579$, nesse mesmo grupo etário ${ }^{30}$. Ainda assim, a razão de rendimento de pessoas ocupadas exprime, em grau de comparação, homens brancos com ganhos mais elevados, seguindo por homens negros, mulheres brancas e mulheres negras.

Para além das desigualdades verificadas acima, pode-se dizer que o mercado de trabalho apresenta significativos contrastes que incluem não somente gênero e cor/raça entre homens e mulheres, mas também entre mulheres brancas e mulheres negras. Em 2016, a proporção de ocupados trabalhando por tempo parcial - até 30 horas semanais - mostra um percentual aproximadamente duas vezes mais elevado de mulheres do que de homens. Entre essas mulheres as pretas ou pardas foram as que mais exerceram ocupação por tempo parcial, alcançando $31,3 \%$ do total, enquanto $25,0 \%$ das mulheres brancas se ocuparam desta forma ${ }^{31}$.

Além de contratações diferenciadas, revelam-se ainda a predominância de interesses e escolhas profissionais distintas entre os gêneros. A distribuição de homens e mulheres em diferentes empregos e carreiras de formação, por exemplo, concentra mulheres em áreas do conhecimento notadamente femininas, como artes, humanas, biológicas e saúde ${ }^{32}$. Tal fenômeno, segundo as autoras, aponta para formas de sexualização das ocupações, produzindo o que chamamos de guetos profissionais femininos.

Dentro dessa assimetria, visualiza-se um quadro de bipolarização. De um lado profissionais qualificadas, com salários relativamente bons em um todo comparativo e, do outro, trabalhadoras de baixa qualificação, em trabalhos precários de baixos salários e tarefas sem reconhecimento, nem valorização. Sobre esta categoria última, revela-se a expressiva participação das trabalhadoras dos serviços domésticos, categoria esta que embora tenha conquistado algumas garantias a partir de sua regulamentação em 2013, também é reconhecida por seus altos níveis de precarização.

\footnotetext{
30 INSTITUTO BRASILEIRO DE GEOGRAFIA E ESTATÍSTICAS. Diferença do rendimento do trabalho de mulheres e homens nos grupos ocupacionais. Pnad Contínua 2018, n. 38, 2018, p. 2. Disponível em: $<$ https://agenciadenoticias.ibge.gov.br/media/com mediaibge/arquivos/694dba51d3592761fcbf9e1a55 d157d9.pdf >. Acesso em: 22 abr. 2020.

${ }^{31}$ INSTITUTO BRASILEIRO DE GEOGRAFIA E ESTATÍSTICAS. Estatísticas de gênero: Indicadores sociais das mulheres no Brasil. Estudos e Pesquisas. Informação Demográfica e Socioeconômica, n. 38, 2018, p. 4. Disponível em: <https://biblioteca.ibge.gov.br/visualizacao/livros/liv101551 informativo.pdf>. Acesso em: 22 abr. 2020.

32 BRUSCHINI, Cristina; LOMBARDI, Maria Rosa. A bipolaridade do trabalho feminino no Brasil contemporâneo. Cad. Pesqui., São Paulo, n. 110, p. 67-104, 2000.
}

LIMA, Flávia T. de; BERGSTRÖM, Gustavo Tank; GEMMA, Sandra F. Bezerra. Reforma trabalhista: contrato intermitente e trabalho feminimo. Revista Jurídica Trabalho e Desenvolvimento Humano, Campinas, v. 3, p. 1-19, 2020. 
Além do trabalho produtivo, a divisão sexual do trabalho favorece recair à mulher o trabalho reprodutivo ou do care ${ }^{33}$, aquele atribuído ao cuidado das crianças, doentes, idosos e a manutenção do lar. Aos homens cabe o papel de provedor da família e aos filhos, sejam homens ou mulheres, o papel de possíveis colaboradores, mas não de responsáveis pelos afazeres domésticos ${ }^{34}$. Isso porque, a identidade feminina vinculada à vocação materna e à afetividade naturaliza formas de dominação que produzem papéis sociais e estereótipos de gênero, visto que encara tais características como habilidades naturais e vocacionais do sexo feminino.

A esse trabalho invisível, não assalariado e não reconhecido impõem-se um acúmulo de atividades que levam a mulher à uma dupla ou muitas vezes, tripla jornada diária, de modo a demandar uma conciliação entre a vida laboral e familiar. Em 2018, as mulheres ocupadas dedicaram 18,5 horas semanais aos afazeres domésticos e cuidados de pessoas, enquanto os homens ocupados gastaram apenas 10,8 horas ${ }^{35}$. Pois, em decorrência do acúmulo de atividades e responsabilidades, pesquisas como a de Angela Maria Carneiro Araújo e Verônica Clemente Ferreira ${ }^{36}$ revelam a incidência de transtornos mentais comuns como ansiedade e depressão em mulheres que exercem trabalho doméstico.

Frente a todas as questões apresentadas, as quais apontam para diferentes formas de segregação sexual da mulher no trabalho, entende-se que a contratação intermitente pode agravar ainda mais a situação das mulheres face à Reforma Trabalhista. Primeiramente porque, como demonstrado, as representações sociais de sexo no trabalho empurram as mulheres para atividades flexíveis e precárias, como a modalidade intermitente. Em seguida, porque incidem sobre elas a permanência das obrigações domésticas e do cuidado como tarefas de

\footnotetext{
${ }^{33}$ GUIMARAES, Nadya Araujo; HIRATA, Helena Sumiko; SUGITA, Kurumi. Cuidado e cuidadoras: $O$ trabalho de care no Brasil, França e Japão. Sociol. Antropol., Rio de Janeiro, v. 1, n. 1, p. 151-180, 2011.

${ }^{34}$ SEGNINI, Liliane Rolfsen Petrilli. Mulheres, mães e desempregadas: contradições de uma condição social. In: EMÍLIO, Marli; TEIXEIRA, Marilane.; NOBRE, Miriam; GODINHO, Tatau (Orgs.). Trabalho e cidadania ativa para mulheres: Desafios para políticas públicas (Coleção Caderno da Coordenadoria Especial da Mulher). São Paulo: Coordenadoria Especial da Mulher, Prefeitura do Município de São Paulo, 2003.

35 INSTITUTO BRASILEIRO DE GEOGRAFIA E ESTATÍSTICAS. Estatísticas de gênero: Indicadores sociais das mulheres no Brasil. Estudos e Pesquisas. Informação Demográfica e Socioeconômica, n. 38, 2018. Disponível em: <https://biblioteca.ibge.gov.br/visualizacao/livros/liv101551 informativo.pdf>. Acesso em: 22 abr. 2020.

${ }^{36}$ ARAÚJO, Angela Maria Carneiro; FERREIRA, Verônica Clemente. Terceirização e relações de gênero. In: DAU, Denise Motta; RODRIGUES, Iram Jácome; CONCEIÇÃO, Jefferson José da (Orgs.) Terceirização no Brasil: do discurso da inovação à precarização do trabalho (atualização do debate e perspectivas). São Paulo: Ed. Annablume, CUT, 2009. p. 129-147, 2009.
} 
Revista Jurídica Trabalho e Desenvolvimento Humano Procuradoria Regional do Trabalho da 15a Região

responsabilidade predominantemente feminina no mundo privado, que impactam a segregação sexuada no mercado de trabalho.

Assim como o trabalho de tempo parcial provoca insegurança no emprego, na carreira e na renda das mulheres ${ }^{37}$, considera-se que o trabalho intermitente possa ter as mesmas consequências. Isso porque, sendo um trabalho não contínuo, demanda-se do sujeito disponibilidade integral ao empregador, o qual define de acordo com suas necessidades o tipo de serviço, o período de trabalho e o rendimento. Considerando os aspectos de conciliação que recaem sobre as mulheres, o empregador tende a exercer, portanto, o controle sobre o tempo de trabalho e não trabalho rentável dessa categoria.

Assim sendo, o trabalho do tipo intermitente reverbera no comprometimento de um planejamento que articule vida familiar e laboral, que inclui a manutenção do lar, a limpeza da casa e das roupas, a alimentação dos membros, a educação das crianças e cuidado com menores, idosos ou pessoas dependentes. Da mesma forma, a variação do número de horas trabalhadas implica também em uma variação financeira que afeta diretamente a organização do trabalho reprodutivo. Sobre tais inseguranças, dentro da inconstância sobre os períodos trabalhados, discute-se também a proporção sobre a contribuição dos fundos previdenciários e o comprometimento da aposentadoria dessa classe.

Como se trata da prestação de serviços alternada a períodos de inatividade, a modalidade de contratação intermitente também afeta a mulher e os direitos concernentes à maternidade. Embora a Reforma traga possibilidade de concessão de benefício à mulher no período considerado de sua licença gestante, é necessário que ela realize contribuições junto ao INSS. Em decorrência da precarização dessa classe, a qual apresenta baixa escolaridade, qualificação e rentabilidade e das responsabilidades atribuídas, muitas vezes, como chefes de família e provedoras do sustento ${ }^{38}$, fica evidente o comprometimento com o respectivo encargo e consequentemente com este amparo legal. O mesmo ocorre em situações de gravidez de risco e acometimento de outras enfermidades.

Do mesmo modo, se estendermos a reflexão sobre as transformações que a Reforma Trabalhista vem trazendo como impacto para a classe feminina, podemos incluir artigos que não apresentam explícita relação com o trabalho da mulher, mas que certamente recaem sobre as

${ }^{37}$ HIRATA, Helena. Globalização, trabalho e gênero. Revista de Políticas Públicas, vol. 9, n. 1, p. 111-128, 2005.

${ }^{38}$ SEGNINI, Liliane Rolfsen Petrilli. Vivências de mulheres em situação de desemprego. São Paulo em Perspectiva, v. 20, n. 4, p. 58-73, out./dez. 2006. 
suas diferentes jornadas. Expressa-se por exemplo o Artigo 456-A, $\S$ único, que define como regra geral a responsabilidade da limpeza do uniforme ao trabalhador, o Artigo 55 que adota o Teletrabalho ou Home Office; o Artigo 58 que retira o direito às horas de deslocamento ao trabalho de difícil acesso, entre outros. Ademais, sendo as mulheres maioria entre a classe de desempregados, entende-se que estas, a fim de evitar o desemprego prolongado, seriam impulsionadas ao trabalho intermitente ${ }^{39}$. Nesse contexto, a falta de trabalho ou emprego, incidiria como fator de incentivo a um cenário crescente de mulheres inseridas nesse tipo de atividade e ao mesmo tempo, reforçador das desigualdades e segregações vividas por elas no trabalho, de forma a contribuir para a reprodução de novas formas de precarização, que revelam no gênero sua sustentação e estrutura.

\section{CONSIDERAÇÕES FINAIS}

Diante do exposto, nota-se que, embora tenha se apresentado uma tentativa de proteção legal a mulher nos moldes da CLT, as representações de gênero construídas social e culturalmente repercutem em uma divisão sexual do trabalho que persiste e revela na realidade cotidiana a segregação de homens e mulheres no trabalho. Com a aprovação da Reforma Trabalhista em 2017, novas formas de flexibilização do trabalho como o contrato intermitente sugerem oportunizar a intensificação da precarização do trabalho e das formas de discriminação de gênero que se agravam em decorrência da cor ou da raça. A desqualificação da mulher no trabalho centra-se exatamente na construção de representações de feminino associadas a qualidades e dons naturais e a manutenção de uma autoridade patriarcal que confere a ela, majoritariamente, a responsabilidade pelas tarefas domésticas, educação dos filhos e cuidado com as crianças, idosos e dependentes. Trabalho este não reconhecido e não remunerado, no qual impera uma conciliação de jornadas que fazem com que as mulheres passem a trabalhar semanalmente aproximadamente duas vezes mais que os homens. Tais aspectos também refletem nas escolhas por determinadas segmentações ocupacionais e polos profissionais tipicamente femininos, destinados comumente as áreas de educação e saúde. No entanto, assim como os trabalhos flexíveis do tipo parcial e temporário, o contrato intermitente segue inserindo

\footnotetext{
${ }^{39}$ TEIXEIRA, Marilane O. A reforma trabalhista e as mulheres. In: TEIXEIRA, Marilane O. (Org). Contribuição crítica à reforma trabalhista. Campinas, SP: UNICAMP/IE/CESIT, 2017, p. 237-261, p. 242.
} 
mulheres em atividades de baixa qualificação, escolaridade e renda, produzindo e aprofundando dinâmicas semelhantes em termos de precarização do trabalho de forma estrutural.

Para além disso, as implicações desta modalidade de contratação prejudicam um planejamento que articule a vida familiar, vida laboral e organização financeira, ao exercer o controle sobre os tempos e ritmos de trabalho dessa categoria. Insere-se como fator agravante o comprometimento contributivo com os encargos sociais, que implica em amparos legais à maternidade, enfermidades, à possível aposentadoria e sua perspectiva de futuro. Além dos reflexos sociais para a saúde e segurança, trabalhos flexíveis como a contratação intermitente possibilitam desgastes mentais significativos derivados da intensificação do trabalho, incentivos à individualidade e competitividade, que corroem as relações solidárias, contribuindo para uma fragmentação da classe trabalhadora como um todo. Frente a tais considerações, entende-se a necessidade de questionar os paradigmas existentes no trabalho, como as construções e representações sociais estabelecidas de forma dominante e segregacionista relativas ao gênero, assim como as dimensões que naturalizam e destinam diferentes atividades e ocupações entre homens e mulheres. Assim, analisa-se como significativa a adoção de políticas públicas articuladas à realidade de destas discussões, de modo a incluir o reconhecimento das atividades realizadas pela mulher no âmbito social e doméstico, sobretudo a fim de possibilitar ações efetivas de igualdade e equidade dentro e fora do trabalho.

\section{REFERÊNCIAS}

ANTUNES, Ricardo. 0 privilégio da servidão: o novo proletariado de serviços na era digital. São Paulo: Boitempo, 2018.

ARAUJO, Tânia Maria de; PINHO, Paloma de Sousa; ALMEIDA, Maura Maria Guimarães de. Prevalência de transtornos mentais comuns em mulheres e sua relação com as características sociodemográficas e o trabalho doméstico. Rev. Bras. Saude Mater. Infant., Recife, v. 5, n. 3, p. 337-348, 2005.

ARAÚJO, Angela Maria Carneiro; FERREIRA, Verônica Clemente. Terceirização e relações de gênero. In: DAU, Denise Motta; RODRIGUES, Iram Jácome; CONCEIÇÃO, Jefferson José da (Orgs.) Terceirização no Brasil: do discurso da inovação à precarização do trabalho (atualização do debate e perspectivas). São Paulo: Ed. Annablume, CUT, 2009, p. 129-147, 2009.

BATISTA, Homero Mateus da Silva. Comentários à Reforma Trabalhista: Análise da Lei 13.456/2017- Artigo por Artigo. São Paulo: Revista dos Tribunais, 2017. 
Revista Jurídica Trabalho e Desenvolvimento Humano Procuradoria Regional do Trabalho da 15a Região

BATISTA, Homero Mateus da Silva. CLT Comentada. 2. ed. São Paulo: Revista dos Tribunais, 2018.

BAUMAN, Zygmunt. Tempos líquidos. Trad. Carlos Alberto Medeiros. Rio de Janeiro: Ed. Jorge Zahar, 2007.

BRASIL. Câmara dos Deputados. Projeto de Lei da Câmara no. 38, de 28 de abril de 2017. Altera a Consolidação das Leis do Trabalho (CLT), aprovada pelo Decreto-Lei no 5.452, de 1ㅇ de maio de 1943, e as Leis nos 6.019, de 3 de janeiro de 1974, 8.036, de 11 de maio de 1990, e 8.212, de 24 de julho de 1991, a fim de adequar a legislação às novas relações de trabalho.

BRASIL. Consolidação das Leis do Trabalho. Decreto-Lei oo 5.452 de 10 de maio de 1943. 1943. Disponível em: <http://www.planalto.gov.br/ccivil 03/decreto-lei/del5452.htm>. Acesso em: 20 de abr. de 2020.

BRASIL. Constituição da República Federativa do Brasil. Texto constitucional promulgado em 5 de outubro de 1988, com as alterações adotadas pelas Emendas Constitucionais nos 1/1992 a 76/2013, pelo Decreto Legislativo no 186/2008 e pelas Emendas Constitucionais de Revisão nos 1 a 6/1994. Disponível em:

<http://www.planalto.gov.br/ccivil 03/constituicao/constituicao.htm >. Acesso em: 20 de abr. de 2020.

BRASIL. Poder Executivo. Projeto de Lei no. 6.787-B, de 23 de dezembro de 2016. Altera o Decreto-Lei no 5.452, de 10 de maio de 1943 - Consolidação das Leis do Trabalho, e a Lei no 6.019, de 3 de janeiro de 1974, para dispor sobre eleições de representantes dos trabalhadores no local de trabalho e sobre trabalho temporário, e dá outras providências.

BRUSCHINI, Cristina; LOMBARDI, Maria Rosa. A bipolaridade do trabalho feminino no Brasil contemporâneo. Cad. Pesqui., São Paulo, n. 110, p. 67-104, 2000.

DELGADO, Mauricio Godinho. Curso de direito do trabalho. 13 ed. São Paulo: LTr, 2014.

FÓRUM ECONÔMICO MUNDIAL. Global Gender Gap Report 2020. Genebra, 2020. Disponível em

<http://www3.weforum.org/docs/WEF GGGR 2020.pdf? ga=2.248336903.1636901091.1587 064995-1004197514.1587064995 > Acesso em 22.04.2020.

GUIMARAES, Nadya Araujo; HIRATA, Helena Sumiko; SUGITA, Kurumi. Cuidado e cuidadoras: O trabalho de care no Brasil, França e Japão. Sociol. Antropol., Rio de Janeiro, v. 1, n. 1, p. 151180, 2011.

HIGA, Flávio da Costa. Reforma trabalhista e contrato de trabalho intermitente. Consultor Jurídico, 8 de junho de 2017. Disponível em: <https://www.conjur.com.br/2017-jun-08/flaviohiga-reforma-trabalhista-contrato-trabalho-intermitente\# ftn11>. Acesso em: 20 de abril de 2020.

HIRATA, Helena. Globalização, trabalho e gênero. Revista de Políticas Públicas. Vol. 9, n. 1, p. 111-128, 2005.

LIMA, Flávia T. de; BERGSTRÖM, Gustavo Tank; GEMMA, Sandra F. Bezerra. Reforma trabalhista: contrato intermitente e trabalho feminimo. Revista Jurídica Trabalho e Desenvolvimento Humano, Campinas, v. 3, p. 1-19, 2020. 
Revista Jurídica Trabalho e Desenvolvimento Humano Procuradoria Regional do Trabalho da 15a Região

HIRATA, Helena; KERGOAT, Danièle. Divisão sexual do trabalho profissional e doméstico: Brasil, França, Japão. In: Costa, Albertina de Oliveira et al. (Orgs.). Mercado de trabalho e gênero: comparações internacionais. Rio de Janeiro: Editora FGV, 2008, p. 263-278.

INSTITUTO BRASILEIRO DE GEOGRAFIA E ESTATÍSTICAS. Diferença do rendimento do trabalho de mulheres e homens nos grupos ocupacionais. Pnad Contínua 2018, n. 38, 2018, p. 2.

Disponível em:

$<$ https://agenciadenoticias.ibge.gov.br/media/com mediaibge/arquivos/694dba51d3592761fc bf9e1a55d157d9.pdf >. Acesso em: 22 abr. 2020.

INSTITUTO BRASILEIRO DE GEOGRAFIA E ESTATÍSTICAS. Estatísticas de gênero: Indicadores sociais das mulheres no Brasil. Estudos e Pesquisas. Informação Demográfica e Socioeconômica, n. 38, 2018. Disponível em:

$<$ https://biblioteca.ibge.gov.br/visualizacao/livros/liv101551 informativo.pdf>. Acesso em: 22 abr. 2020.

KERGOAT, Danièle. Divisão sexual do trabalho e relações sociais de sexo. In: HIRATA, Helena; LABORIE, Françoise ; LE DOARE, Hélène, SENOTIER, Danièle. (Orgs.). Dicionário Crítico do feminismo. São Paulo: Edunesp, 2009.

KREIN, José Dari; OLIVEIRA, Roberto Veras. Para além do discurso: impactos efetivos da Reforma nas formas de contratação. In KREIN, José Dari; OLIVEIRA, Roberto Veras; FILGUEIRAS, Vitor Araújo (Orgs). Reforma trabalhista no Brasil: promessas e realidade. Campinas: Curt Nimuendajú, 2019.

KREIN, José Dari; OLIVEIRA, Roberto Veras; FILGUEIRAS, Vitor Araújo (Orgs). Reforma trabalhista no Brasil: promessas e realidade. Campinas: Curt Nimuendajú, 2019.

LEITE, Marcia de Paula. As bordadeiras de Ibitinga: trabalho a domicílio e prática sindical. Cadernos Pagu, Campinas, n. 32, p. 183-214, 2009.

MELO, Raimundo Simão de. Impactos da Reforma Trabalhista sobre o Meio Ambiente do Trabalho e a Saúde dos Trabalhadores. Revista do Advogado, n. 137, p.144-153, mar. 2018.

NASCIMENTO, Amauri Mascaro. Curso de direito do trabalho. 14. ed. São Paulo: Saraiva, 2013.

NEVES, Magda de Almeida. Trabalho feminino, flexibilidade e qualificação. Trabalho e Educação, Belo Horizonte, v. 21, n. 2, p. 11-28, 2012.

REPÓRTER BRASIL. Reforma trabalhista: maior parte da mídia não aborda o impacto negativo das mudanças. Publicado pela Repórter Brasil em 05 de junho de 2017. Disponível em: $<$ https://reporterbrasil.org.br/2017/06/reforma-trabalhista-maior-parte-da-midia-nao-abordao-impacto-negativo-das-mudancas >. Acesso em: 20 abr. de 2020.

SEGNINI, Liliane Rolfsen Petrilli. Mulheres, mães e desempregadas: contradições de uma condição social. In: EMÍLIO, Marli; TEIXEIRA, Marilane.; NOBRE, Miriam; GODINHO, Tatau (Orgs.). Trabalho e cidadania ativa para mulheres: Desafios para políticas públicas (Coleção 
Caderno da Coordenadoria Especial da Mulher). São Paulo: Coordenadoria Especial da Mulher, Prefeitura do Município de São Paulo, 2003.

SEGNINI, Liliane Rolfsen Petrilli. Vivências de mulheres em situação de desemprego. São Paulo em Perspectiva, v. 20, n. 4, p. 58-73, out./dez. 2006.

TEIXEIRA, Marilane Oliveira et al. (Org). Contribuição crítica à reforma trabalhista. Campinas, SP: UNICAMP, Instituto de Economia/CESIT, 2017.

TEIXEIRA, Marilane O. A reforma trabalhista e as mulheres. In: TEIXEIRA, Marilane $O$.

(Org). Contribuição crítica à reforma trabalhista. Campinas, SP: UNICAMP/IE/CESIT, 2017, p. 237-261.

WAJCMAN, J. Tecnologia de produção: fazendo um trabalho de gênero. Cadernos Pagu, n. 10, p. 201-256, 1 jan. 2012. 